\title{
Origin of the midurethral sling operation
}

\author{
Peter E. P. Petros ${ }^{1,2,3}$
}

Received: 17 January 2017 / Accepted: 17 February 2017 /Published online: 10 March 2017

(C) The International Urogynecological Association 2017

I write to congratulate Peter Dwyer on his career achievements and contributions to the International Urogynecology Journal. At least in my view, Peter Dwyer and Paul Riss have taken the journal from a middle ranking journal to the unchallenged leader in the urogynecology field. Truly an admirable achievement! Looked at in relation to the scale of these achievements, writing to correct what I see as a minor error seems almost churlish! The correction is to do with the origin of the midurethral sling. Just as Peter Dwyer acknowledges the influence of his teachers on his career, so I have always acknowledged an intellectual debt to Robert Zacharin, starting with the first edition of my textbook in 2004.

It is correct to state that the midurethral sling operation was inspired by Dr. Zacharin's anatomical work. However, the technique for the midurethral sling was entirely my own creation and it was based on my own experimental animal studies carried out at the Royal Perth Hospital in the years 1987 and 1988, where a tape inserted at the midurethra

Peter Dwyer

My mentors in urogynecology

Int Urogynecol J (2016) 27:1783-1784 doi:10.1007/s00192-016-3171-9

Electronic supplementary material The online version of this article (doi:10.1007/s00192-017-3301-z) contains supplementary material, which is available to authorized users.

Peter E. P. Petros

pp@kvinno.com

31/93 Elizabeth Bay Rd, Elizabeth Bay, NSW 2011, Australia

2 Professorial Department of Surgery, St Vincent's Hospital Sydney, University of NSW, Sydney, NSW, Australia

3 School of Mechanical and Chemical Engineering, University of Western Australia, Perth, WA, Australia created an artificial collagenous neoligament to reinforce the weakened pubourethral ligament [1]. The full discovery process was published in the International Urogynecology Journal in 2015 [2].

\section{Compliance with ethical standards}

Conflicts of interest None.

\section{References}

1. Petros PE, Ulmsten U, Papadimitriou J. The autogenic neoligament procedure: a technique for planned formation of an artificial neoligament. Acta Obstet Gynecol Scand. 1990;69 Suppl 153:43-51.

2. Petros PEP. Creating a gold standard surgical device: scientific discoveries leading to TVT and beyond: Ulf Ulmsten Memorial Lecture 2014. Int Urogynecol J. 2015;26(4):471-476. doi:10.1007/s00192015-2639-3. 